\title{
Separation of matrix alloy and reinforcement from aluminum metal matrix composites scrap by salt flux addition
}

\author{
K R RAVI, R M PILLAI*, B C PAI and M CHAKRABORTY ${ }^{\dagger}$ \\ Materials and Minerals Division, Regional Research Laboratory (CSIR), Thiruvananthapuram 695 019, India \\ ${ }^{\dagger}$ Metallurgical and Materials Engineering, Indian Institute of Technology, Kharagpur 721 302, India
}

MS received 28 November 2006

\begin{abstract}
Separation of matrix alloy and reinforcements from pure $\mathrm{Al}-\mathrm{SiC}_{\mathrm{p}}$ composite scrap by salt flux addition has been theoretically predicted using interface free energies. Experiments performed confirm the theoretical prediction. Complete separation of matrix aluminum and reinforcement from metal matrix composites (MMCs) scrap has been achieved by addition of $2.05 \mathrm{wt} \%$ of equimolar mixture of $\mathrm{NaCl}-\mathrm{KCl}$ salt flux with a metal and particle yield of 84 and $50 \%$, respectively. By adding $5 \mathrm{wt} \%$ of $\mathrm{NaF}$ to equimolar mixture of $\mathrm{NaCl}-$ KCl, metal and particle yield improved to 91 and $73 \%$, respectively. Reusability of both the matrix aluminum and the $\mathrm{SiC}$ separated from $\mathrm{Al}-\mathrm{SiC}_{\mathrm{p}}$ scraps has been analysed using XRD, SEM and DTA techniques. The matrix alloy separated from $\mathrm{Al}-\mathrm{SiC}_{\mathrm{p}}$ scraps can be used possibly as a low Si content $\mathrm{Al}-\mathrm{Si}$ alloy. However, the interfacial reaction that occurred during the fabrication of the composites had degraded the SiC particles.
\end{abstract}

Keywords. Metal matrix composites; salt flux; separation; recycling.

\section{Introduction}

The application of metal matrix composites (MMCs) in many engineering components has increased over the last few years, particularly in the automobile industry as drive shafts, engine and brake components (Chawla and Chawla 2006). It is mainly due to the ever increasing restrictions on the fuel consumption and emission, which have forced the automotive manufacturers to look for newer light weight materials. Recent MMCs market survey released by the Business Communications Company (BCC) confirms that MMCs consumption in automotive sector increased from 1.57-2.03 million $\mathrm{kg}$ during the period 1999-2004 (Chawla and Chawla 2006). BCC projects a rise from its 2004 level of $2.03-2.9$ million $\mathrm{kg}$ by 2010 , which corresponds to an average annual growth rate of $6.2 \%$. The amount of MMCs scraps (feeder heads, runners and rejected and worn out components) generated during manufacturing and service will increase as the world consumption increases. Therefore, development of viable techniques for recycling and reclamation of MMCs is essential and critical to the commercialization of these advanced materials.

The problems associated with conventional recycling of Al MMCs by remelting are (i) amplified interfacial reaction between the melt and the reinforcement (mainly in low Si content wrought alloys) and (ii) tendency to the formation of large quantities of dross. Separation of both the matrix aluminum and the reinforcement from Al MMCs

\footnotetext{
*Author for correspondence (rmpillai_rrl@yahoo.com)
}

scrap and reuse them individually is an alternate approach. The energy requirement for recycled aluminum alloy ingot is only about $3 \%$ of that of primary ingot (Ohnishi 1996). This fact also strongly supports the separation process.

Generally, oxide films and insoluble metallic and nonmetallic inclusions are separated from aluminum melt by salt flux addition (Roy and Sahai 1998). This technique can also be used to separate the aluminum alloy and reinforcement from Al MMCs scrap. The most commonly used salt fluxes are mixtures of $\mathrm{NaCl}$ and $\mathrm{KCl}$ (Schuster et al 1993). Besides these chlorides, fluorides are also added to improve the fluxing efficiency. In the present study, separation of the matrix alloy and the reinforcements from pure $\mathrm{Al}-\mathrm{SiC}_{\mathrm{p}}$ composites by salt flux addition has been theoretically predicted using interface free energies followed by experimental validation. Further, the reusability of both the matrix aluminum and $\mathrm{SiC}$ separated from pure $\mathrm{Al}-\mathrm{SiC}_{\mathrm{p}}$ composites scraps has been analysed using $\mathrm{XRD}, \mathrm{SEM}$ and DTA techniques.

\section{Theoretical aspects of separation}

MMCs consist of a matrix metal and a reinforcement, which have their own crystal structure and interfaces between them. The entropy of mixing in the fabrication of MMCs does not change much because MMCs are not mixtures at atomic level. This indicates that there should be a way to separate reinforcements from the matrix.

During the fabrication of MMCs, the minimum work, $W$, required is given by 


$$
W=\left(\gamma_{\mathrm{rm}}-\gamma_{\mathrm{ra}}\right) d A,
$$

where $\gamma_{\mathrm{rm}}$ is the interface energy between reinforcement and matrix metal, $\gamma_{\mathrm{ra}}$ the surface energy of the reinforcement surrounded by air before the fabrication of the MMCs, and $d A$ the total interface area between matrix metal and reinforcement of an unit weight of MMCs (figure $1(\mathrm{a})$ ). When ceramic fibres or particles are used as the reinforcement, $\gamma_{\mathrm{rm}}$ is much larger than $\gamma_{\mathrm{ra}}$, because the contact angle between the molten matrix metal and the reinforcement is larger than $90^{\circ}$. Hence, when some stimulus is given to the interface, the separation of the reinforcement might occur because the interface has a driving force. However, the separation occurs spontaneously only when the interface free energy $\left(\Delta G_{1}\right)$ is negative.

$$
\Delta G_{1}=\gamma_{\mathrm{ra}} d A_{1}+\gamma_{\mathrm{ma}} d A_{2}-\gamma_{\mathrm{rm}} d A,
$$

where $\gamma_{\mathrm{ma}}$ is the surface energy of the matrix surrounded by air during fabrication of the composite and $d A_{1}$ and $d A_{2}$ are surface area of reinforcement and matrix metal at the interface, respectively after separation (figure 1(b)). For metal-ceramic system, $\Delta G_{1}$ is always positive, because the driving force available according to (1) is compensated by the energy required to create two new surfaces. Hence, the separation of reinforcements from composite does not occur spontaneously.

In order to separate matrix alloy and reinforcement, it is important to find a material that makes an interface having smaller interface energy than the matrix metal, when the material contacts the reinforcement. The salt fluxes are found to be candidate material for separation process (Ohnishi 1996). When it comes into contact with the interface between reinforcement and matrix metal at the molten state (figure 2(a)), it infiltrates into the interface instead of the matrix metal as shown in figure 2(b). The interface free energy of this case is given by

$$
\Delta G_{2}=\gamma_{\mathrm{rf}} d A_{3}+\gamma_{\mathrm{mf}} d A_{4}-\gamma_{\mathrm{rm}} d A,
$$

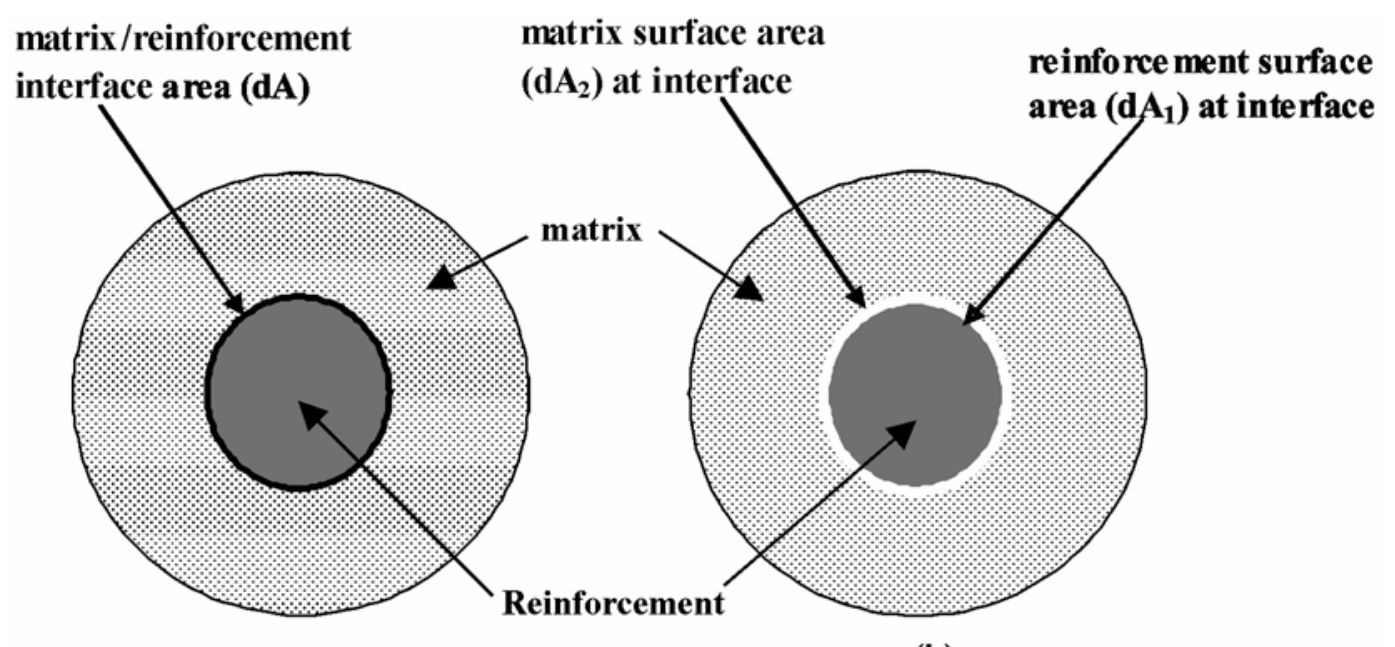

(a)

(b)

Figure 1. Surface area at the interface prior to flux addition: (a) before separation and (b) after separation.

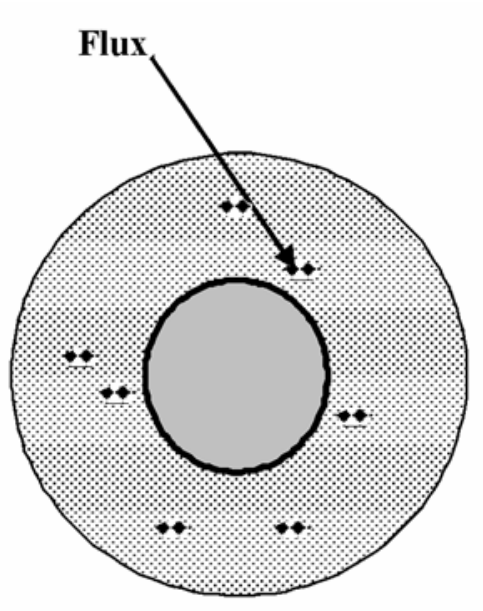

(a)

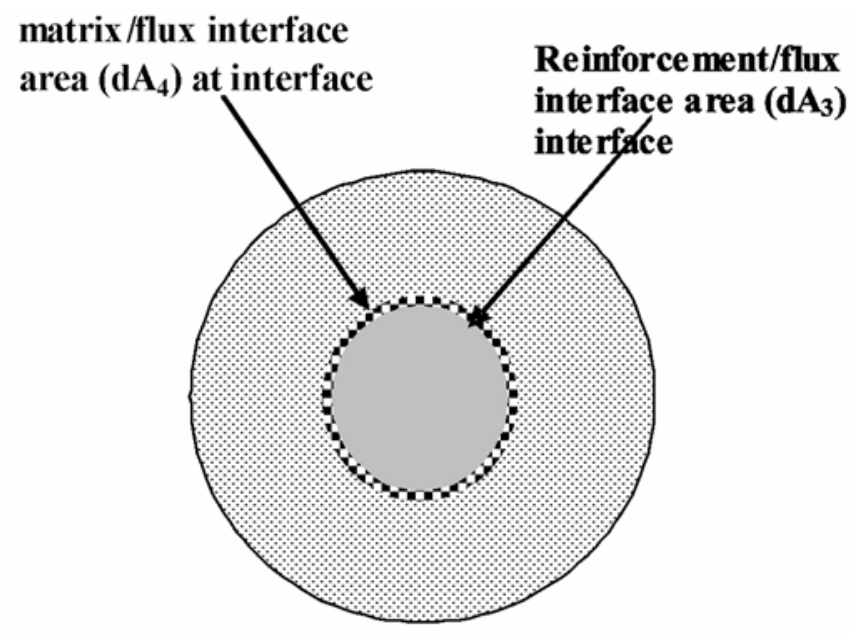

(b)

Figure 2. Surface area at the interface after flux addition: (a) before separation and (b) after separation. 
where $\gamma_{\mathrm{rf}}$ is the interface energy between the reinforcement and the flux, $\gamma_{\mathrm{mf}}$ the interface energy between the metal and the flux, $d A_{3}$ the total interface area between reinforcement and flux and $d A_{4}$ the total interface area between matrix and flux.

Assuming $d A=d A_{3}=d A_{4}$, since the difference between these three interface areas is very small,

$$
\Delta G_{3}=\left(\gamma_{\mathrm{rf}}+\gamma_{\mathrm{mf}}-\gamma_{\mathrm{rm}}\right) d A .
$$

When $\Delta G_{3}$ is less than zero and the salt fluxes have only little solubility in the matrix metal, separation of the matrix metal and the reinforcement from composite is spontaneous.

\subsection{Interfacial tension between ceramic reinforcement and molten salt flux $\left(\gamma_{r f}\right)$}

When the contact angle between two materials is rather low, it is possible to estimate the interface energy by Girifalco and Good's (1957) equation

$$
\gamma_{\mathrm{rf}}=\gamma_{\mathrm{ra}}+\gamma_{\mathrm{f}}-2 \phi\left(\gamma_{\mathrm{ra}} \cdot \gamma_{\mathrm{f}}\right)^{1 / 2} \text {, }
$$

where $\gamma_{\mathrm{f}}$ is the surface tension of molten salt flux and $\phi$ a constant which is determined by the characteristics of the system.

\subsection{Interfacial tension between molten aluminum and salt flux $\left(\gamma_{m f}\right)$}

When the interfacial tension changes due to the adsorption of surface active elements, Girifalco and Good's (1957) equation in conjunction with expressions for the surface coverage of surface active species can be used to estimate the interfacial tension. In the present work, interfacial tension between molten aluminum and various salt flux systems has been taken from the plot showing the variation of interfacial tension between aluminum and equimolar $\mathrm{NaCl}-\mathrm{KCl}$ as a function of $\mathrm{NaF}$ addition (Roy and Utigard 1998).

\subsection{Interfacial tension between ceramic reinforcement and molten aluminum $\left(\gamma_{\mathrm{rm}}\right)$}

The interfacial tension between the ceramic particles and the liquid aluminum, $\gamma_{\mathrm{rm}}$ is calculated using Young's equation

$$
\gamma_{\mathrm{rm}}=\gamma_{\mathrm{ra}}-\gamma_{\mathrm{ma}} \cos \theta
$$

\section{Materials and methods}

Pure $\mathrm{Al}-\mathrm{SiC}_{\mathrm{p}}$ composites used in the present study have been fabricated by stir casting technique. Entire composite fabrication process (particle addition, stirring and pouring) has been carried out at $720^{\circ} \mathrm{C}$. The time of contact of the aluminum melt with $\mathrm{SiC}$ at this temperature did not exceed $30 \mathrm{~min}$. In order to change the interfacial energy between the ceramic reinforcement and the matrix metal at molten state, equimolar mixture of $\mathrm{NaCl}-\mathrm{KCl}$ salt flux with varying amounts of $\operatorname{NaF}(1,2,3,4,5,7$ and $10 \mathrm{wt} \%)$ has been added to the composite melt through vortex created by mechanical stirring at $700^{\circ} \mathrm{C}$. At a certain quantity of flux addition, separation of reinforcement particles starts leading to their floating on the melt surface and skimming off. The left over matrix melt in the crucible has been poured into a cast iron mold.

\section{Results and discussion}

\subsection{Comparison of theoretical model and experimental results}

The effect of equimolar mixture of $\mathrm{NaCl}-\mathrm{KCl}$ salt flux addition to pure $\mathrm{Al}-\mathrm{SiC}$ composites on free energy for separation $\left(\Delta G_{3}\right)$ has been theoretically calculated using the values of various parameters given in appendix 1 . According to the theoretical result, the free energy for the separation in $\mathrm{Al}-\mathrm{SiC}$ composites is negative $\left(-48 \mathrm{~mJ} / \mathrm{m}^{2}\right) d A$ with equimolar mixture of $\mathrm{NaCl}-\mathrm{KCl}$ salt flux addition. It indicates that separation of $\mathrm{SiC}$ particle from $\mathrm{Al}-\mathrm{SiC}$ composites melt should occur with equimolar mixture of $\mathrm{NaCl}-\mathrm{KCl}$ salt flux addition. Experiments performed confirm the theoretical results. Addition of $2.05 \mathrm{wt} \%$ equimolar mixture of $\mathrm{NaCl}-\mathrm{KCl}$ salt flux results in complete separation of the matrix material and the reinforcement from MMCs scrap with metal and particle yield of 84 and $50 \%$, respectively. The balance metal and particle form a part of the dross generated.

The effect of $\mathrm{NaF}$ addition to equimolar mixture of $\mathrm{NaCl}-\mathrm{KCl}$ salt flux on the free energy and optimum quantity

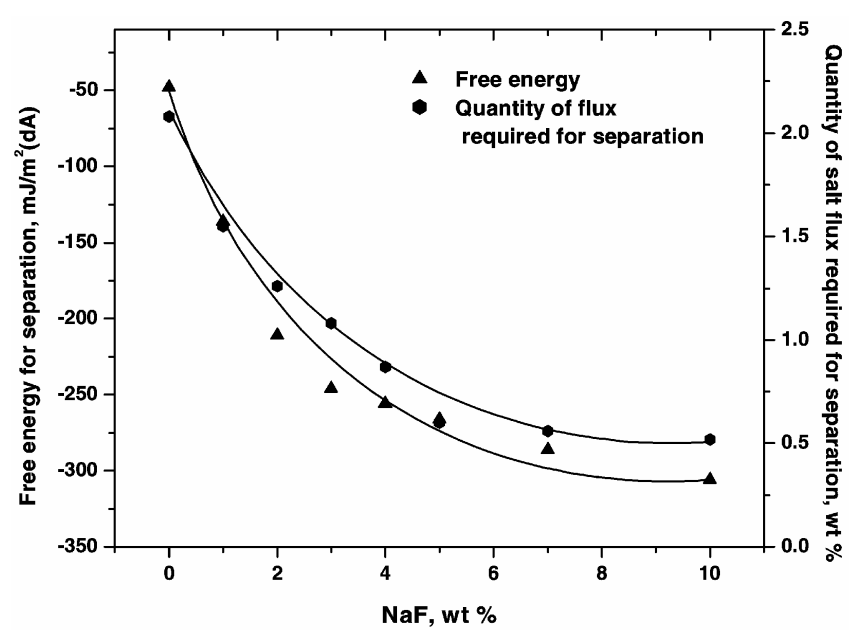

Figure 3. Influence of $\mathrm{NaF}$ addition to equimolar mixture of $\mathrm{NaCl}-\mathrm{KCl}$ salt flux on the free energy and optimum quantity of flux required for separation in pure $\mathrm{Al}-\mathrm{SiC}_{\mathrm{p}}$ composites. 


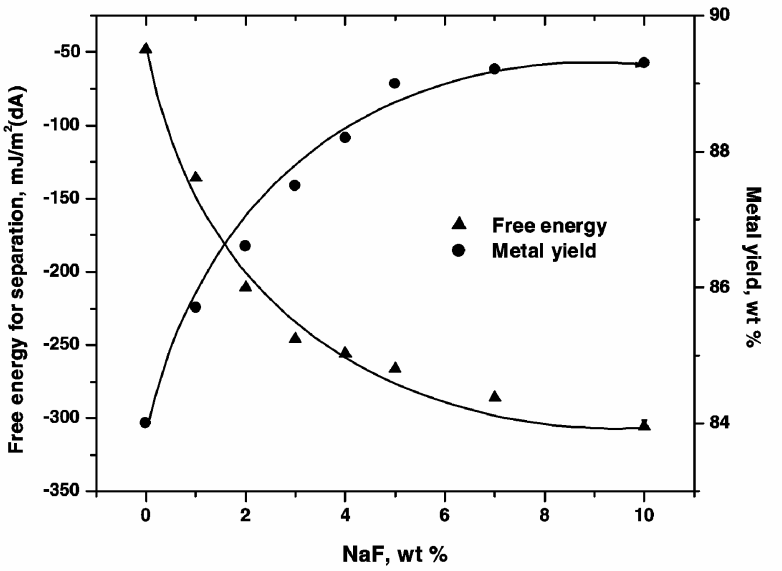

(a)

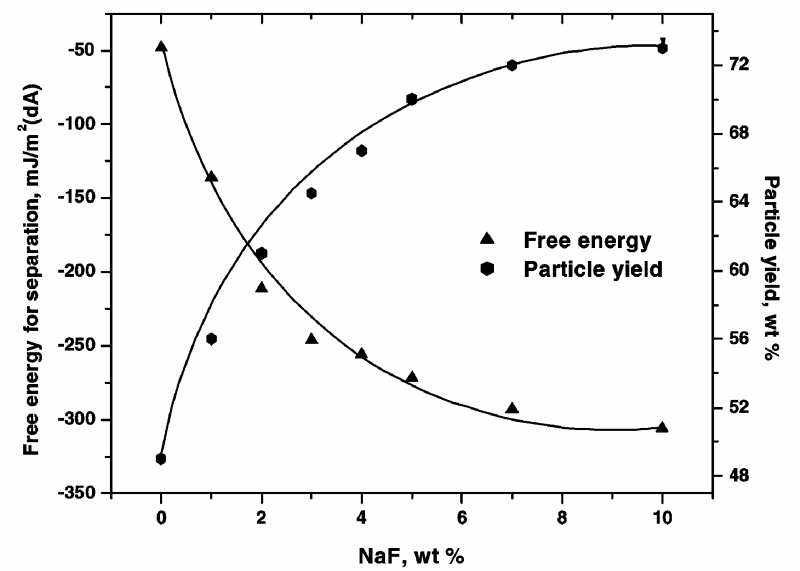

(b)

Figure 4. Influence of $\mathrm{NaF}$ addition to equimolar mixture of $\mathrm{NaCl}-\mathrm{KCl}$ salt flux on (a) metal yield and (b) reinforcement yield in pure $\mathrm{Al}-\mathrm{SiC}_{\mathrm{p}}$ composites.

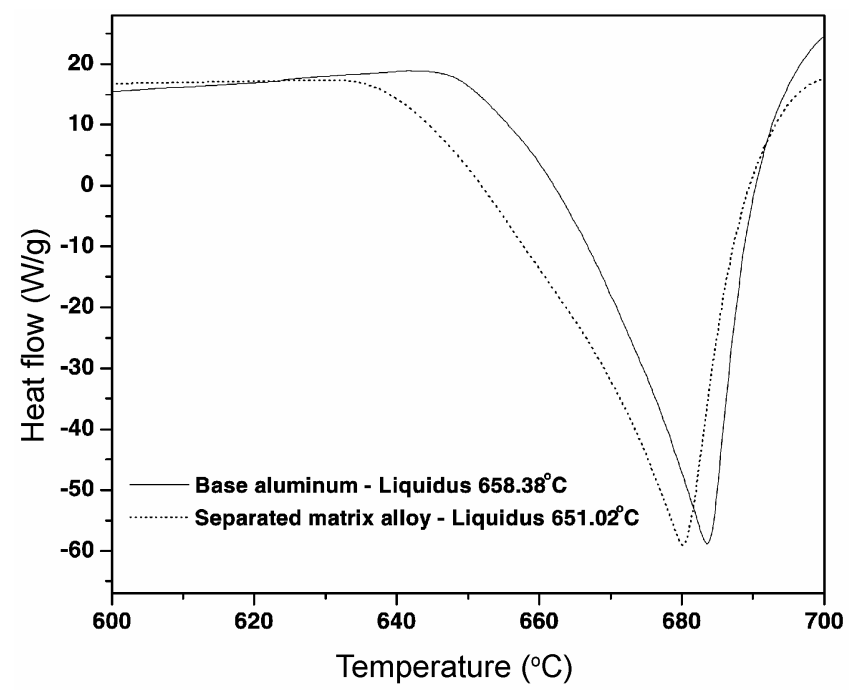

Figure 5. DTA heating curves of pure aluminum and matrix alloy separated from pure $\mathrm{Al}-\mathrm{SiC}_{\mathrm{p}}$ composites (as processed) by salt flux (equimolar $\mathrm{NaCl}-\mathrm{KCl}+5 \mathrm{wt} \% \mathrm{NaF}$ ) addition.

of flux required for separation in pure $\mathrm{Al}-\mathrm{SiC}$ composites is shown in figure 3 . The free energy for separation decreases rapidly from $\left(-48 \mathrm{~mJ} / \mathrm{m}^{2}\right) d A$ to $\left(-266 \mathrm{~mJ} / \mathrm{m}^{2}\right) d A$ up to $5 \mathrm{wt} \%$ of $\mathrm{NaF}$ addition to equimolar mixture of $\mathrm{NaCl}-$ $\mathrm{KCl}$ salt flux and thereafter, it decreases slowly from $\left(-266 \mathrm{~mJ} / \mathrm{m}^{2}\right) d A$ to $\left(-306 \mathrm{~mJ} / \mathrm{m}^{2}\right) d A$ with further $5 \mathrm{wt} \%$ of $\mathrm{NaF}$ addition. Similarly, optimum quantity of salt flux required for separation decreases from $2.05 \mathrm{wt} \%$ to $0.6 \mathrm{wt} \%$ with $5 \mathrm{wt} \%$ of $\mathrm{NaF}$ addition to equimolar mixture of $\mathrm{NaCl}-\mathrm{KCl}$ salt flux and with further $5 \mathrm{wt} \%$ of $\mathrm{NaF}$ addition it decreased to $0.52 \mathrm{wt} \%$. Further, metal and particle yield improved to 91 and $73 \%$, respectively with $5 \mathrm{wt} \%$ of $\mathrm{NaF}$ addition to equimolar mixture of $\mathrm{NaCl}-\mathrm{KCl}$ salt flux (figures 4(a) and (b)). These results indicate that the free energy for separation calculated based on the

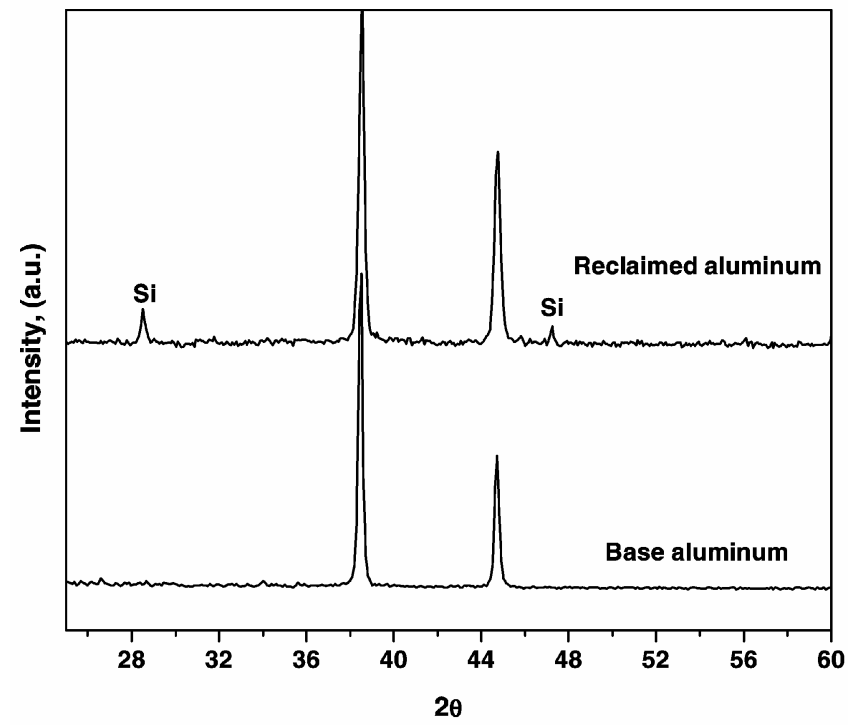

Figure 6. Comparison of XRD patterns of matrix alloy separated from pure $\mathrm{Al}-\mathrm{SiC}_{\mathrm{p}}$ composites (as processed) by salt flux (equimolar $\mathrm{NaCl}-\mathrm{KCl}+5 \mathrm{wt} \% \mathrm{NaF}$ ) addition with that of pure aluminum.

interface energy is in qualitative agreement with the efficiency of separation process. The increase in the separation efficiency promoted by $\mathrm{NaF}$ addition to the equimolar mixture of $\mathrm{NaCl}-\mathrm{KCl}$ salt flux has been attributed to the simultaneous action of three factors: (i) the free energy for separation $\left(\Delta G_{3}\right)$ becoming more negative, (ii) decrease in flux viscosity favouring the coalescence of aluminum (Roy and Sahai 1997) and (iii) removal of alumina $\left(\mathrm{Al}_{2} \mathrm{O}_{3}\right)$ film formed on the melt surface acting as a physical barrier to the transfer of separated particles to the melt surface. Hence, continuous stripping of oxide layer from the melt surface is necessary for effective separation of reinforcement. This observation is in agreement with that of 

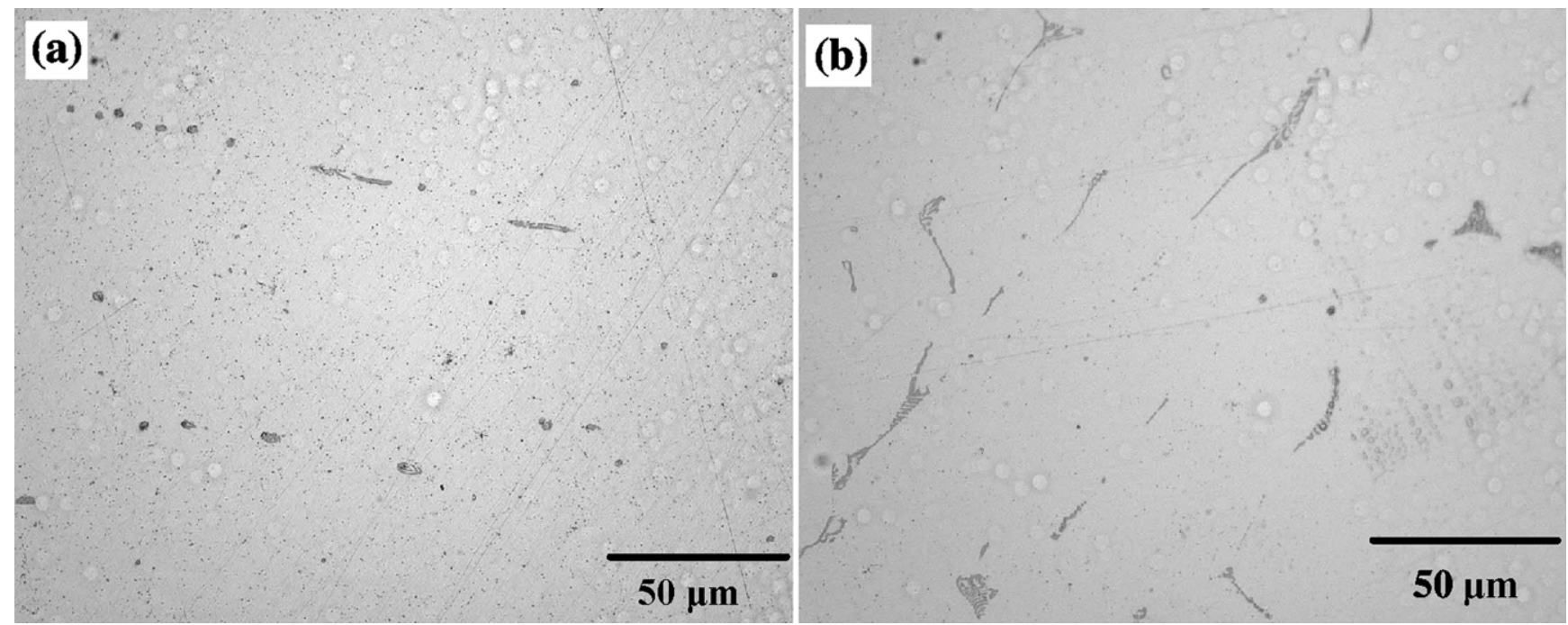

Figure 7. Optical microstructure of (a) pure aluminum and (b) matrix alloy separated from pure $\mathrm{Al}_{-} \mathrm{SiC}_{\mathrm{p}}$ composites (as processed) by salt flux (equimolar $\mathrm{NaCl}-\mathrm{KCl}+5 \mathrm{wt} \% \mathrm{NaF}$ ) addition.
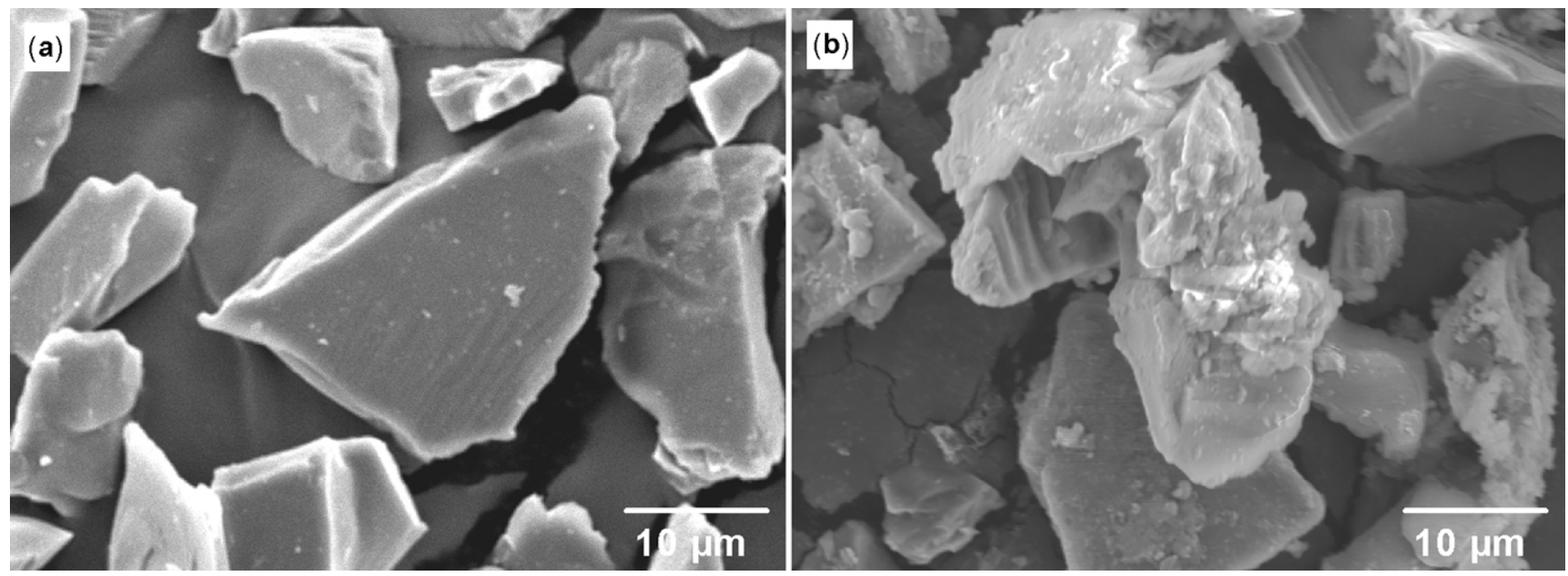

Figure 8. Scanning electron micrograph of (a) as received $\mathrm{SiC}$ particles and (b) $\mathrm{SiC}$ particles separated by equimolar NaCl$\mathrm{KCl}+5 \mathrm{wt} \% \mathrm{NaF}$ salt flux addition.

Ye and Sahai (1996), who have also added $\mathrm{NaF}$ to equimolar mixture of $\mathrm{NaCl}-\mathrm{KCl}$ salt flux to remove the external oxide layer of aluminum melt more efficiently.

\subsection{Recycling of separated matrix alloy}

During the fabrication of pure $\mathrm{Al}-\mathrm{SiC}_{\mathrm{p}}$ composites via stir casting process, it is impossible to avoid the interfacial reaction totally due to the low $\mathrm{Si}$ contents within the matrices (Lee et al 1999). Interfacial reaction between $\mathrm{Al}$ and $\mathrm{SiC}$ to form $\mathrm{Al}_{4} \mathrm{C}_{3}$ and $\mathrm{Si}$ takes place according to the reaction

$$
4 \mathrm{Al}+3 \mathrm{SiC} \leftrightarrow \mathrm{Al}_{4} \mathrm{C}_{3}+3 \mathrm{Si} .
$$

$\mathrm{Si}$ released during this interfacial reaction changes the matrix alloy composition resulting in a decrease in liquidus temperature. This decrease in liquidus temperature can be ascertained by differential thermal analysis (DTA). Figure 5 shows the DTA heating curves of pure aluminum and the matrix alloy separated from pure $\mathrm{Al}-\mathrm{SiC}_{\mathrm{p}}$ composites (as processed) by salt flux (equimolar $\mathrm{NaCl}-\mathrm{KCl}+5 \mathrm{wt} \%$ $\mathrm{NaF}$ ) addition. In the case of pure aluminum, upon heating, a strong endothermic peak appears at around $658.38^{\circ} \mathrm{C}$, corresponding to the melting of the matrix alloy. Considering that the melting of pure $\mathrm{Al}$ occurs at $660^{\circ} \mathrm{C}$, the measured melting temperature of the $\mathrm{Al} / \mathrm{SiC}_{\mathrm{p}}$ composite in its as processed condition is slightly lower, which may be attributed to the presence of small amounts of impurities within the matrix. In the case of separated matrix alloy, the thermal response observed is similar to that for the pure aluminum except at a lower melting temperature of $651.02^{\circ} \mathrm{C}$. XRD of separated matrix alloy shows diffraction peak of the released $\mathrm{Si}$ (figure 6), which is responsible for the decrease in liquidus tempera- 
ture in DTA curve of separated matrix aluminum. It indicates that interfacial reaction has occurred during processing of composite at $720^{\circ} \mathrm{C}$ for $30 \mathrm{~min}$.

Figure 7 shows the optical microstructure of pure aluminum and matrix alloy separated from pure $\mathrm{Al}-\mathrm{SiC}_{\mathrm{p}}$ composite, the latter showing the typical microstructure of low $\mathrm{Si}$ content hypoeutectic Al-Si alloy. In the separated matrix alloy, no reinforcement particle is observed. This shows that complete separation of matrix metal and reinforcement from $\mathrm{Al}-\mathrm{SiC}_{\mathrm{p}}$ composites scrap has been achieved by salt flux addition. Hence, the separated matrix aluminum can be reused possibly as a low Si content Al-Si alloy.

\subsection{Recycling of separated SiC particles}

Figure 8(a) shows the sharp edges and smooth surface morphologies of $\mathrm{SiC}_{\mathrm{p}}$ in as-received condition, while figure 8 (b) reveals the rounded edges and degraded surfaces of the $\mathrm{SiC}_{\mathrm{p}}$ separated from pure $\mathrm{Al}-\mathrm{SiC}_{\mathrm{p}}$ composites (as processed) by salt flux (equimolar $\mathrm{NaCl}-\mathrm{KCl}+5 \mathrm{wt} \%$ $\mathrm{NaF}$ ) addition indicating the occurrence of interfacial reaction during processing of the composites. The sharp corners are chemically more reactive due to their high surface energy. XRD results obtained from $\mathrm{SiC}_{\mathrm{p}}$ separated from pure $\mathrm{Al}-\mathrm{SiC}_{\mathrm{p}}$ composites shows $\mathrm{Al}_{4} \mathrm{C}_{3}$ peak (figure 9), further confirming the interfacial reaction. Thus, the interfacial reaction taking place during the fabrication of the composite degrades the $\mathrm{SiC}$ particles limiting its recyclability.

\section{Conclusions}

(I) Theoretically predicted separation of matrix alloy and reinforcements from pure $\mathrm{Al}-\mathrm{SiC}_{\mathrm{p}}$ composite scrap by salt flux addition has been confirmed by experiments.

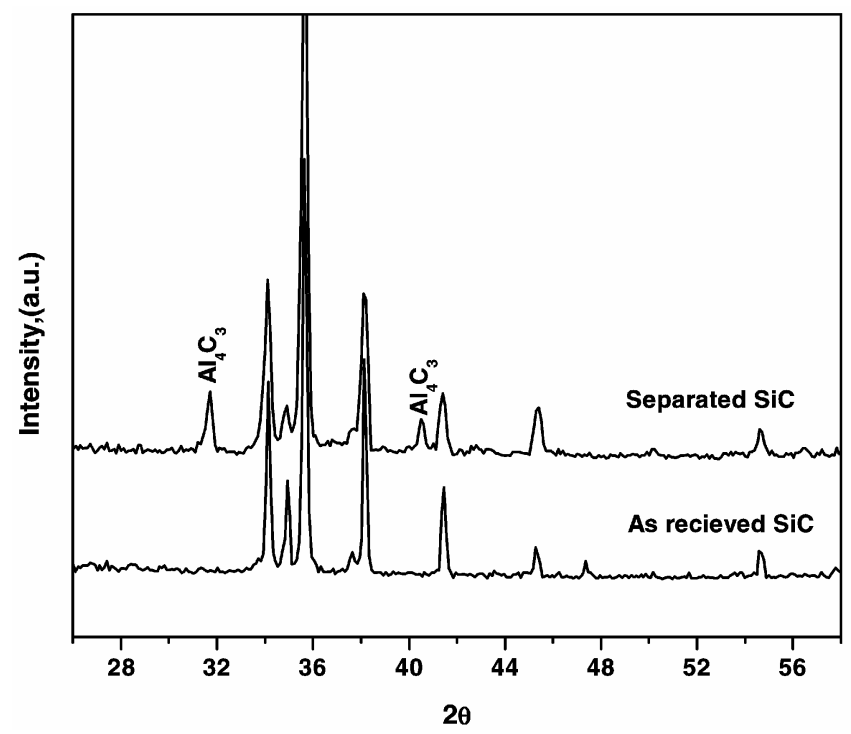

Figure 9. Comparison of XRD patterns of $\mathrm{SiC}$ particles separated by equimolar $\mathrm{NaCl}-\mathrm{KCl}+5 \mathrm{wt} \% \mathrm{NaF}$ salt flux addition with that of as received $\mathrm{SiC}$ particles.
(II) Addition of equimolar mixture of $\mathrm{NaCl}-\mathrm{KCl}$ salt flux results in complete separation of matrix material and reinforcement from MMCs scrap with metal and particle yield of $84 \%$ and $50 \%$, respectively.

(III) Additon of $5 \mathrm{wt} \% \mathrm{NaF}$ to equimolar mixture of $\mathrm{NaCl}-\mathrm{KCl}$, metal and particle yield has been improved to 91 and $73 \%$, respectively.

(IV) Separated matrix aluminum can be reused possibly as a low Si content $\mathrm{Al}-\mathrm{Si}$ alloy.

(V) Interfacial reaction taking place during fabrication of the composites degrades the SiC particles limiting their recyclability.

\section{Appendix I}

Interface energies:

$\gamma_{\mathrm{ra}}=1844 \mathrm{~mJ} / \mathrm{m}^{2}$ (Barsoum and Ownby 1981);

$\phi=0.41$ (Silny and Utigard 1997; Ho and Sahai 1990);

$\gamma_{\mathrm{f}}=106 \mathrm{~mJ} / \mathrm{m}^{2}$ (Silny and Utigard 1997; Ho and Sahai 1990);

$\gamma_{\mathrm{ma}}=1007 \mathrm{~mJ} / \mathrm{m}^{2}$ (Anson et al 1999).

Contact angle between $\mathrm{Al}$ and $\mathrm{SiC}=120 \mathrm{deg}$ (Laurent et al 1987).

\section{Acknowledgements}

The authors thank the Council of Scientific and Industrial Research, New Delhi, for the award of a senior research fellowship to the first author, $\mathrm{Mr}$ M R Chandran for scanning electron microscopy and Mr S G K Pillai for optical microscopy.

\section{References}

Anson J P, Drew R A L and Gruzleski J E 1999 Met. Mater. Trans. B30 1027

Barsoum M W and Ownby P D 1981 Surfaces and interfaces in ceramic metals systems (New York: Plenum Press) p. 463

Chawla N and Chawla K K 2006 JOM 5867

Girifalco L A and Good R J 1957 J. Phys. Chem. 61904

Handbook of Chemistry and Physics 1981 CRC Press, 66th edn. p. F-20

Ho F K and Sahai Y 1990 Light Met. 717

Laurent V, Chattain D and Eustathopoulos N 1987 J. Mater. Sci. 22244

Lee J C, Seok HK and Lee H I 1999 Mater. Res. Bull. 34 35

Ohnishi T 1996 J. Jpn Inst. Light Met. 46525

Roy R R and Sahai Y 1997 Mater. Trans. JIM 38568

Roy R R and Utigard T A 1998 Met. Mater. Trans. B29 821

Roy R R and Sahai Y 1998 Light metals (Warrendale, Pennsylvania: TMS Annual Meeting) pp 1237-1243

Schuster D M, Skibo M D, Bruski R S, Provencher R and Riverin G 1993 JOM 4626

Silny A and Utigard T A 1997 Light Met. 871

Ye J and Sahai Y 1996 Mater. Trans. JIM 37175 